\title{
Chapter 17 \\ Impacts of the Nuclear Power Plant Accident and the Start of Trial Operations in Fukushima Fisheries
}

\author{
Nobuyuki Yagi
}

\begin{abstract}
The large-scale release of radioactive substances from the Fukushima Daiichi Nuclear Power Plant operated by the Tokyo Electric Power Company in March 2011 caused significant damage to local fisheries. The Fukushima Prefectural Federation of Fisheries Cooperative Associations immediately suspended all commercial fishing activities within Fukushima. The national government issued instructions prohibiting the sale of certain marine products caught in the waters off Fukushima Prefecture due to food safety concerns. The prohibition is gradually being lifted; in June 2012, the Fisheries Cooperative Associations resumed commercial fishing of three species (two octopus species and one shellfish species) as trial operations. Subsequently, the list has expanded, and as of January 2015, 58 species have been approved for trial operations. The scale of operations is far smaller than before the tsunami and nuclear accident. A full recovery of Fukushima fisheries cannot be realized until the government lifts prohibitions on the sale of all remaining marine species, and the timing of such a decision remains unclear.
\end{abstract}

Keywords Cesium • Fukushima • Radioactive substances • Trial fishery

\subsection{Introduction}

The tsunami on March 11, 2011 damaged around 29,000 fishing boats and 319 fishing ports in Japan (Fisheries Agency of Japan 2014a). Each of these figures accounts for approximately $10 \%$ of the respective national totals. Since October 31,2014 , approximately 17,713 of these boats and 302 of the ports have again become operational (Fisheries Agency of Japan 2014a). Despite the unprecedented scale of the disaster, the rehabilitation of the fisheries in the tsunami-damaged areas, excluding Fukushima Prefecture, has been relatively expeditious in terms of fishing capacity as measured by the number of boats and ports (Yagi 2014).

\footnotetext{
N. Yagi $(\bowtie)$

Graduate School of Agricultural and Life Sciences, The University of Tokyo, 1-1-1 Yayoi,

Bunkyo, Tokyo 113-8657, Japan

e-mail: yagi@fs.a.u-tokyo.ac.jp
} 
In Fukushima Prefecture, significant damage has been caused by the large-scale release of radioactive substances from the Fukushima Daiichi Nuclear Power Plant operated by the Tokyo Electric Power Company (TEPCO). The recovery of fishing capacity has been slower in Fukushima than in the other two tsunami-damaged prefectures, namely Iwate and Miyagi. A total of 873 fishing vessels were damaged by the tsunami in Fukushima Prefecture (Ministry of Agriculture, Forestry and Fisheries, Japan 2012). As of October 31, 2014, 327 fishing vessels and 8 fishing ports in Fukushima Prefecture have been repaired or reconstructed (Fisheries Agency of Japan 2014a). Nonetheless, as of January 2015, most fisheries in Fukushima have not been able to resume their commercial operations due to nuclear damage.

This chapter of the book reviews the state of fisheries in Fukushima since the nuclear power plant accident. It also provides precise records regarding the start of trial operations in June 2012. Finally, the discussion section is provided that considers future options for fisheries in Fukushima.

\subsection{Commercial Fisheries in Fukushima Before and After the Disaster}

Within the waters of Fukushima, ${ }^{1}$ roughly 10 different fisheries were being operated until the nuclear accident in 2011. These fisheries included bottom trawling, mid-water trawling, purse seine, gill net, saury dip net, trap net, long line, line and pole (jigging), pot fishery, and hand gathering. The national and prefectural governments set a licensing system and various regulations, such as total allowable catches (TACs) for several species, restrictions on gear use, and restricted areas of operations for each fishery. While purse seine and saury dip net fisheries can be operated both inside and outside the waters of Fukushima, the other eight fisheries were in principle only allowed inside the waters of Fukushima.

The average landing volume of fisheries in Fukushima before the disaster was approximately 50 thousand metric tons per year (Fukushima Prefecture 2011, 2012). Of these, bottom trawling, mid-water trawling, and purse seine fisheries were the three major fisheries. Table 17.1 provides an overview of the areas of operations, the main target species, and the average annual landing volumes before the nuclear accident.

Figure 17.1 provides time series data on annual landings. On average, approximately 40-50 thousand metric tons of annual landings were recorded by Fukushima fisheries before the disaster, but this decreased to less than 5 thousand metric tons after the nuclear accident (Fukushima Prefecture 2011, 2012, 2013). Landings from

\footnotetext{
${ }^{1}$ The term "waters of Fukushima" used in this chapter refers to ocean areas bounded by the coastline of Fukushima Prefecture, the outer limit of Japan's Exclusive Economic Zone, and the boundaries with Miyagi and Ibaraki prefectures (see Fig. 17.2).
} 
Table 17.1 Fisheries in Fukushima before the nuclear accident

\begin{tabular}{l|l|l|l}
\hline Type of fishery & Main target species & $\begin{array}{l}\text { Area of } \\
\text { operation }\end{array}$ & $\begin{array}{l}\text { Annual landing (in metric } \\
\text { tons) }\end{array}$ \\
\hline Bottom trawling & $\begin{array}{l}\text { Pacific cod, flatfish, } \\
\text { octopus }\end{array}$ & Offshore & 10,588 \\
\hline $\begin{array}{l}\text { Mid-water } \\
\text { trawling }\end{array}$ & $\begin{array}{l}\text { Sand lance larvae } \\
\text { (whitebait) }\end{array}$ & Coastal & 10,156 \\
\hline Purse seine & Skipjack tuna, mackerel & $\begin{array}{l}\text { Offshore/ } \\
\text { outside }\end{array}$ & 18,253 \\
\hline Gill net & $\begin{array}{l}\text { Spanish mackerel, } \\
\text { yellowtail }\end{array}$ & $\begin{array}{l}\text { Coastal/ } \\
\text { offshore }\end{array}$ & 2496 \\
\hline Saury dip net & Pacific saury & $\begin{array}{l}\text { Offshore/ } \\
\text { outside }\end{array}$ & 5803 \\
\hline Trap net & Chum salmon, sea bass & Coastal & 276 \\
\hline Long-line & Pacific cod & Coastal & 207 \\
\hline $\begin{array}{l}\text { Line and pole, } \\
\text { jigging }\end{array}$ & $\begin{array}{l}\text { Skipjack tuna, bigeye } \\
\text { tuna }\end{array}$ & $\begin{array}{l}\text { Coastal/ } \\
\text { offshore }\end{array}$ & 1111 \\
\hline Pot fishery & Octopus, shellfish & $\begin{array}{l}\text { Coastal/ } \\
\text { offshore }\end{array}$ & 1098 \\
\hline Hand gathering & Shellfish, seaweed & Shoreline & 84 \\
\hline
\end{tabular}

Source: Compiled by the author based on information available from the Fukushima Prefectural Government

"Annual landing" refers to the average annual landing reported from 2001 to 2010 at ports in Fukushima Prefecture. The figures include landings by Japanese fishing boats registered in both Fukushima and other prefectures in Japan. They do not include landings by Fukushima vessels at ports outside of Fukushima Prefecture. "Offshore/outside" refers to offshore areas of waters in Fukushima and other prefectures in Japan. "Offshore/coastal" refers to both offshore and coastal areas in Fukushima Prefecture

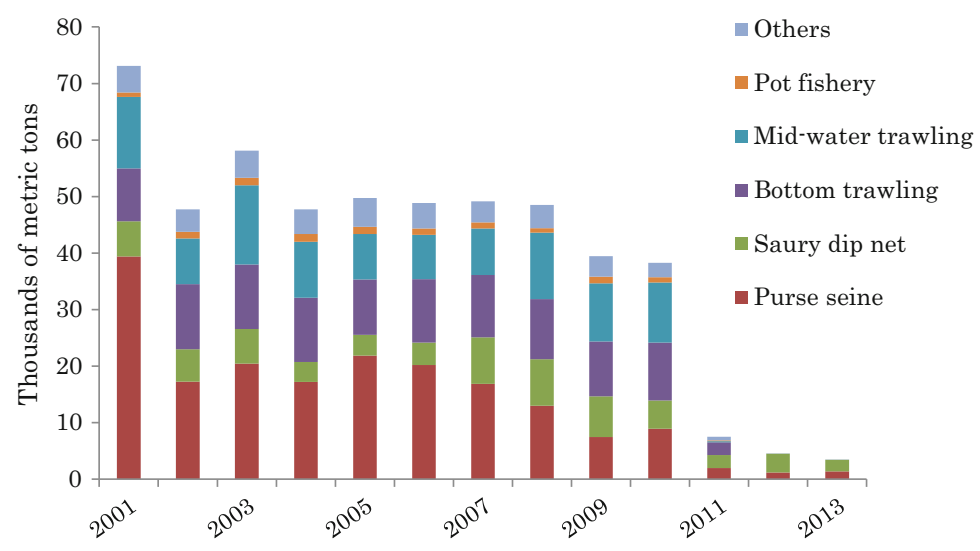

Fig. 17.1 Commercial landings from fisheries in Fukushima. These figures include landings by Japanese fishing boats registered in both Fukushima and other prefectures in Japan. They do not include landings by Fukushima vessels at ports outside of Fukushima Prefecture. Landings from “trial fishing” after June 2012 are not included (Source: Fukushima Prefecture 2011, 2012, 2013) 
2012 to 2013 were harvested with purse seines and saury dip net fisheries outside the waters of Fukushima and then landed in the ports of Fukushima Prefecture. The landings in 2011 include ordinary commercial harvests from January to March $11,2011$.

\subsection{Initiation of Trial Operations in Fukushima Fisheries}

As a result of the large-scale release of radioactive substances from the Fukushima Daiichi Nuclear Power Plant following the earthquake and tsunami of March 11, 2011, the Fukushima Prefectural Federation of Fisheries Cooperative Associations (hereafter referred to as the Fukushima FCA) decided on March 15, 2011 to voluntarily stop fishing operations in the waters of Fukushima (Yagi 2014). Some fishing activities in the prefectures neighboring Fukushima (namely Miyagi and Ibaraki) were also suspended after the TEPCO accident, but most of these were subsequently reopened within 2 years (Ibaraki Prefecture 2014; Miyagi Prefecture 2014).

Neither the national nor the prefectural governments revoked fishing licenses in Fukushima. However, the national government did provide legally binding sales prohibitions on certain marine products caught in the waters off Fukushima Prefecture based on the food safety requirements. The Japanese government set the allowable level of radioactive cesium for all fisheries products as $500 \mathrm{~Bq} / \mathrm{kg}$ until it was reduced to $100 \mathrm{~Bq} / \mathrm{kg}$ on April 1, 2012 (Fisheries Agency of Japan 2014b). In addition, species-specific prohibitions on sales and marketing for specific agricultural and fishery products, originating from certain areas were introduced by the government regardless of the actual measured levels of radioactive substances.

Many of the fishers in Fukushima have been receiving a certain level of compensation from TEPCO since the nuclear accident (Yagi 2013). According to the law, the nuclear power plant operator TEPCO should compensate fishers for stopping their operations in Fukushima (Fisheries Agency of Japan 2012). Although TEPCO is paying compensation, many fishers have complaints. Some fishers are unable to submit evidence that could be used to calculate the amount of actual damage, because sales slips dated before the accident were lost during the tsunami, resulting in inappropriate compensation to such fishers. Processing and/or distribution companies are considering leaving Fukushima, as they cannot get adequate compensation. Furthermore, fishers can neither estimate how long they need to cease their operations nor make long-term plans for the future (Yagi 2013).

Within this context, the Fukushima FCA launched the "Fukushima Prefectural Fisheries Reconstruction Committee" in 2012 with the aim of reconstructing the fisheries industry and restarting fisheries operations. The author is a member of this committee and took note as a participant that the committee discussed issues including the following (Yagi 2014). 
- From January 1, 2012 to June 4, 2012, Fukushima Prefecture analyzed 2118 samples of marine organisms collected from the waters of Fukushima. The survey showed that the level of radioactive substances in fish is site-specific. The levels were higher in samples collected near the nuclear plant and became lower in samples collected in deeper ocean areas. The levels of radioactivity are also species-specific and invertebrate species contained less cesium in 2011 and levels dropped to zero in 2012.

- On the other hand, as of June 2012, more than $100 \mathrm{~Bq} / \mathrm{kg}$ of radioactive cesium was still being recorded in Japanese sea bass and other fish species living along the coast.

- An independent biological study has showed that fish species have their own function for excreting cesium from their bodies (Furukawa et al. 2012).

- These findings are consistent with the International Atomic Energy Agency (IAEA) report that shows marine invertebrate animals have low concentration factors compared with fish (figures calculated by dividing the level of cesium contained in the body by the level of cesium contained in the water) (IAEA 2004).

In June 2012, after taking into account the above information considered by the Fukushima Prefectural Fisheries Reconstruction Committee, the Fukushima FCA decided to resume fishing activities, named as "trial operations," for three species (two octopus species and one shellfish species) living at depths of more than $150 \mathrm{~m}$ in ocean areas approximately $60-90 \mathrm{~km}$ from the damaged nuclear power plant. Because the government did not revoke fishing licenses for fishers in Fukushima after the nuclear power plant accident, the fishers were left to decide for themselves whether to resume commercial fisheries by targeting species that met government food safety standards.

The trial operation has several limitations, and therefore it is not regarded as a full resumption of commercial fisheries. The limitations include: (1) days of operation (usually fewer than 5 days a month); (2) landing ports (only two ports have been designated: one in Soma and the other in Iwaki); (3) the amount of landed fish (usually less than 10 tons a day); and (4) the number of vessels involved in fishing operations (Yagi 2014). Operation rules are set in order to maintain a high frequency of monitoring for radioactive substances and to ensure traceability following landing of marine products.

Figure 17.2 shows the areas for trial operations. Initially the trial operations for bottom trawling were only allowed in Area 1 . This area was expanded to include Area 2 in October 2012, Area 3 in February 2013, Area 4 in May 2013, Area 5 in August 2013, and Area 6 in December 2013. The pot fishery was limited to Areas 1, 2, 3, and 4 in 2013. Trial operations for mid-water trawling started in March 2013 and are allowed in Area A. In February 2014, such operations were added to Area B.

The Fukushima FCA for a certain number of samples conducts monitoring of radioactive cesium at landing sites. These samples are randomly selected, but they do not cover every fisheries product, and because the testing method involves 


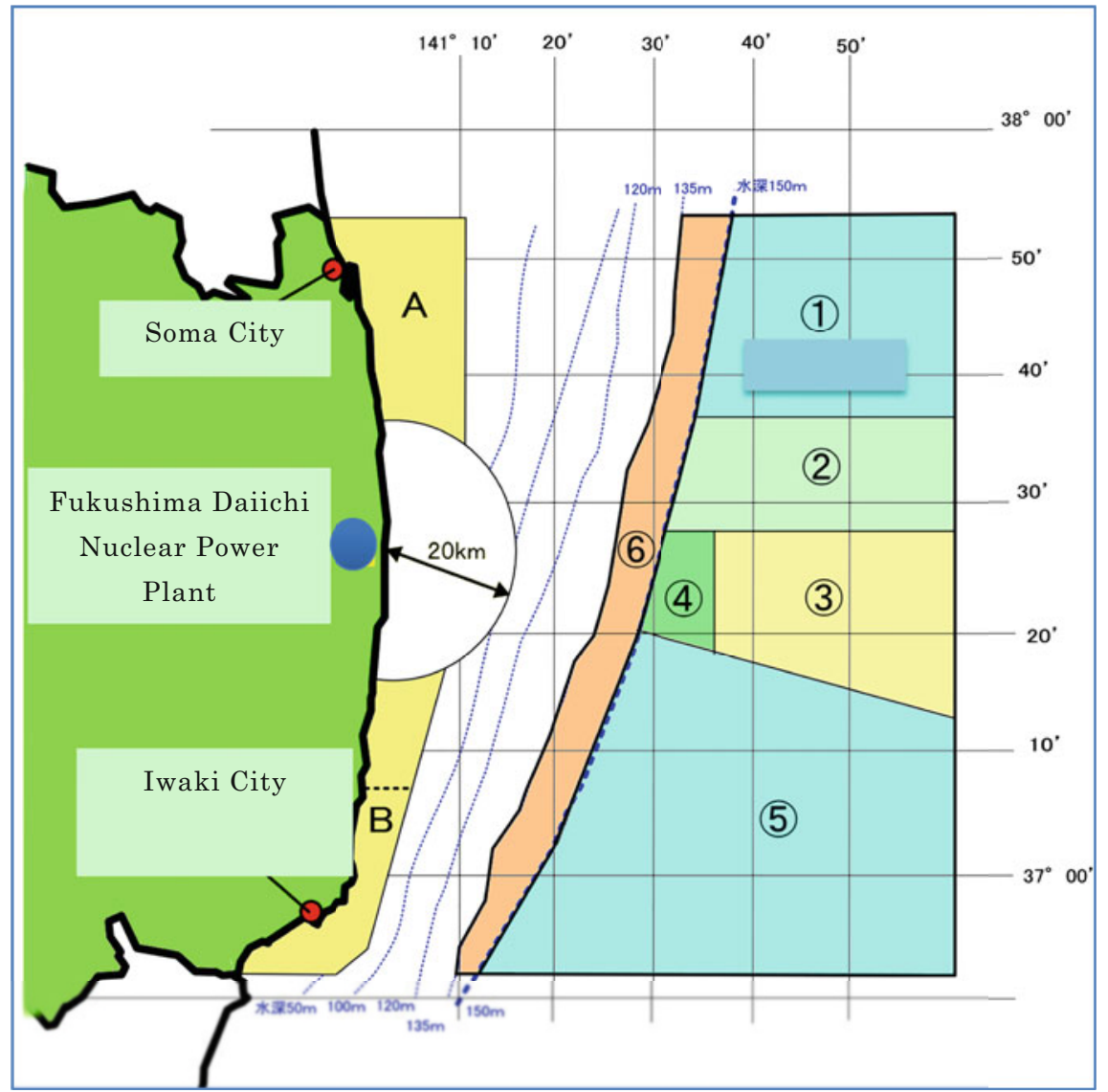

Fig. 17.2 Areas for trial operations (Source: Fukushima FCA http://www.fsgyoren.jf-net.ne.jp/ siso/buhin/kaiiki20140827.pdf)

grinding up the fish, the tested samples are not marketable afterwards. When any product exceeds the Fukushima FCA's voluntary standard level, ${ }^{2}$ which is $50 \mathrm{~Bq} / \mathrm{kg}$ of radioactive substances, all products are immediately recalled (Yagi 2014).

Landed octopus and shellfish have been sold with labels indicating Fukushima as their point of origin (Yagi 2014). Most of these products were sold at local supermarkets in Fukushima, and sold out very quickly, most likely due to the small quantity of available items and a number of consumers wishing to help their local fishers by purchasing their products (Yagi 2014).

Figure 17.3 indicates the scale of the trial operations. As of January 2015, the trial operations are only being allowed for bottom trawling, mid-water trawling, and

\footnotetext{
${ }^{2}$ Although the threshold set by the government is $100 \mathrm{~Bq} / \mathrm{kg}$, the Fukushima FCA decided to set a more conservative limit of $50 \mathrm{~Bq} / \mathrm{kg}$ as its voluntary standard.
} 


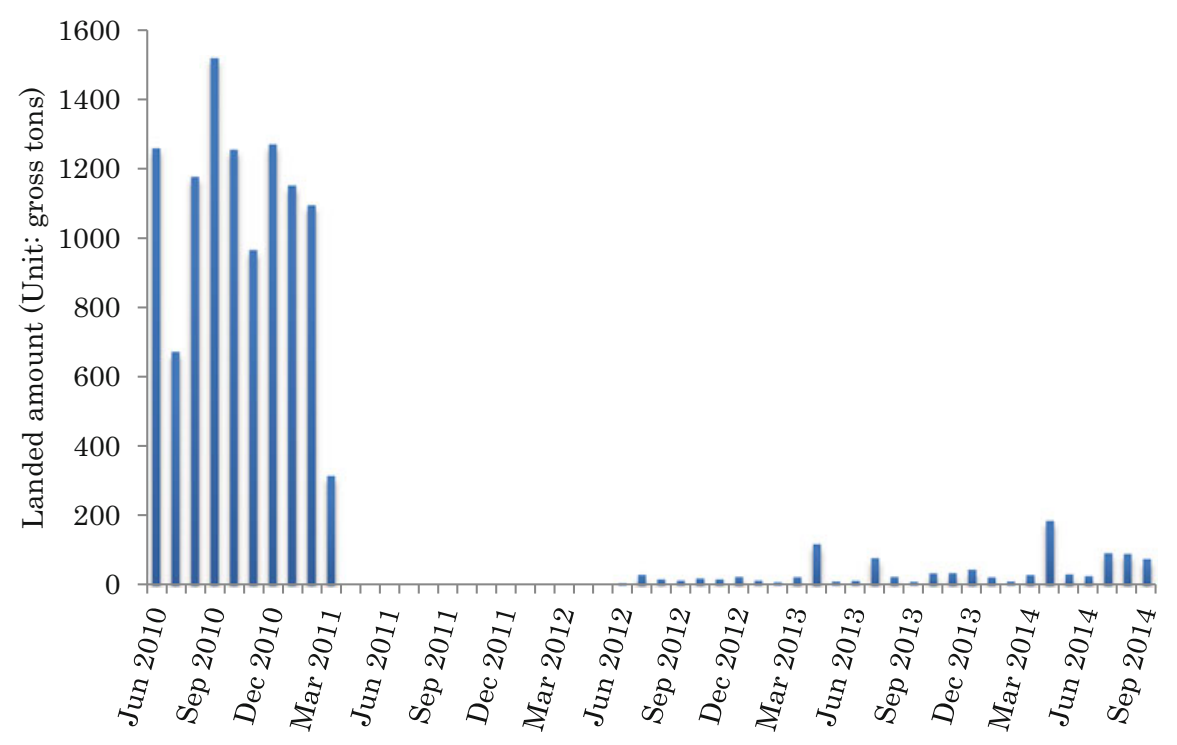

Fig. 17.3 Monthly landings of commercial fisheries before the nuclear accident in March 2011 and since trial operations started in June 2012. Data were compiled by the author using information available from Fukushima Prefecture

pot fishery. The monthly average landing of the three fisheries used to be around 1200 gross tons before the disaster in March 2011. The landings under the trial operations, however, are around 40 gross tons per month, or approximately 1/30th of those recorded before the disaster.

The committee also discussed how some consumers are likely to object to the limited resumption of fishing activities due to concerns that fishing operations should not be allowed at all when there is a risk of consumers ingesting radioactive substances contained in fish products (Yagi 2014). Some consumers may also object to only checking radioactive substances in some samples and not in the full catch. The committee argued that "Each individual has a right to select what they want. Rather than trying to persuade consumers that Fukushima products on the market are safe, it is better to clearly label the products as originating from Fukushima and to allow consumers to make their own decisions about consumption behavior" (Yagi 2014).

The number of species allowed under the trial fishery operations gradually expanded in 2012: seven species were added in August, and another three species were added in November. An additional 18 species were added to the list over the course of 2013. Thus, a total of 31 species were subject to trial fishery operations as of February 2014 (Fukushima FCA 2014). The number subsequently increased, and 58 species are now allowed under the trial fishery operations as of January 2015. 


\subsection{State of Radioactive Substances in Marine Species}

Since the nuclear power plant accident in March 2011, various governmental institutes have collected and analyzed samples of marine organisms and released information on levels of radioactive substances. One of the most extensive datasets for the testing results is available through the website of the Fisheries Agency of the Government of Japan (http://www.jfa.maff.go.jp/j/housyanou/kekka.html). The data includes information on each analyzed sample with respect to its species name, sampling area, its level $(\mathrm{Bq} / \mathrm{kg})$ of radioactive cesium 134 and 137, date of sampling, and the name of the institution that analyzed the sample. Data are available for 27,283 samples collected inside Fukushima Prefecture and another 39,228 from outside of Fukushima Prefecture. Of the samples collected outside Fukushima, approximately $6.5 \%$ of the samples of marine species contained radioactive cesium above $100 \mathrm{~Bq} / \mathrm{kg}$ between March and June 2011. From July 2011 to March 2012, approximately $5 \%$ of the samples contained radioactive cesium above $100 \mathrm{~Bq} / \mathrm{kg}$. The proportion of samples that contained radioactive cesium above $100 \mathrm{~Bq} / \mathrm{kg}$ gradually decreased during 2012. Since 2013, less than $1 \%$ of samples collected outside the waters of Fukushima contained radioactive cesium above $100 \mathrm{~Bq} / \mathrm{kg}$.

The status of samples collected from within the waters of Fukushima is somewhat different (see Fig. 17.4). Fukushima Prefecture has regularly been collecting samples of marine species from all areas across the waters in Fukushima since March 2011. In April 2011, 13 samples were collected, and it was found that 12 of them $(92 \%)$ contained radioactive cesium over the level of $100 \mathrm{~Bq} / \mathrm{kg}$ (Fukushima Prefecture website: http://www.pref.fukushima.lg.jp/sec/36035e/suisanka-monitatop.html). Thereafter, 32 samples out of $47(68 \%)$ in May, 72 samples out of $145(50 \%)$ in June, 95 samples out of 201 (47\%) in July, and 103 samples out of $238(43 \%)$ samples in August contained radioactive cesium in excess of $100 \mathrm{~Bq} / \mathrm{kg}$. During this early period after the disaster, the monthly sample size was less than 300 , but this has subsequently increased to around 700 samples per month (see

Fig. 17.4). From September 2011 to April 2012, more than $20 \%$ of the sampled marine species contained radioactive cesium over $100 \mathrm{~Bq} / \mathrm{kg}$. For the first half of 2013, 3-8 \% of samples contained cesium over $100 \mathrm{~Bq} / \mathrm{kg}$, and after July 2013, the proportion dropped to $0-2 \%$.

Detailed outcomes of the tests above are also available from Wada et al. (2013). Several other analyses have also been published by independent researchers from outside the government. Kikkawa et al. (2014), for instance, used published data for 8683 samples of aquatic animals and plants obtained off the coast of Fukushima from 2011 to 2013 and evaluated the level of radioactive cesium $\left({ }^{134} \mathrm{Cs}\right.$ and $\left.{ }^{137} \mathrm{Cs}\right)$ for 95 species (a total of 97 fishery items including two species that are marketed separately at the adult and immature stages). A cluster analysis based on parameters of annual average and standard deviation of radioactive cesium concentration levels indicated that the 97 items can be categorized into four groups. The first group had lower concentrations and lower variability across the first and second years 


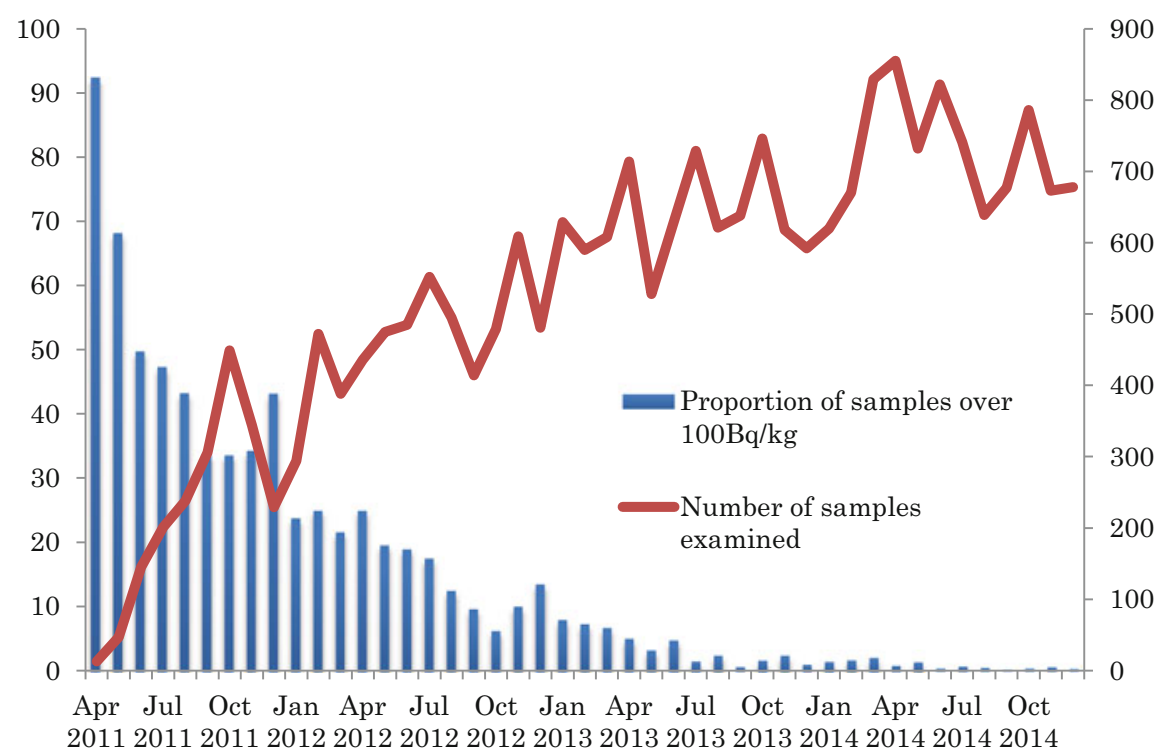

Fig. 17.4 Levels of radioactive cesium in marine species sampled in the waters of Fukushima between April 2011 and December 2014. The left axis indicates the percentage of samples that contained over $100 \mathrm{~Bq} / \mathrm{kg}$ of radioactive cesium. The right axis shows the number of samples examined per month. The figure is compiled by the author using data available from the Fukushima Prefectural Government http://www.pref.fukushima.lg.jp/sec/36035e/suisankamonita-top.html

(60 items); the second group showed a decline in concentration levels in the second year, but remained high (21 items); the third group had extremely high initial concentrations, but levels became almost undetectable in the second year (1 item); and the fourth group exhibited high contamination levels across the 2 years (15 items) (Kikkawa et al. 2014). The researchers argue that almost all of the items in the first and third groups satisfied the government's food safety standards in the second year. On the other hand, products in the second and the fourth groups do not satisfy these standards, and must be closely monitored (Kikkawa et al. 2014).

The names of species that are subject to sales prohibitions have been announced by the Government of Japan. The sales prohibition is legally binding and the government periodically revises the list based on the best available information. Since December 2013, the prohibition has been in effect for 40 marine species living in the waters of Fukushima (Fukushima Prefecture 2014), and since January 2015, it has been reduced to 35 species (Fukushima Prefecture 2015).

On the other hand, the target species for the trial operations are decided by the Fukushima FCA in consultation with the Fukushima Prefectural Fisheries Reconstruction Committee, and they discuss the most recent testing results for radioactive substances in all marine species. As of January 2015, 58 species are allowed for trial 
operations. In sum, approximately 200-300 marine fish and invertebrate species occur in the waters of Fukushima, and 58 of these are targeted by the trial operations, while 35 other species are prohibited for sale due to government regulations. The rest are still subject to monitoring for radioactive substances by research institutions, but are not treated as species for trial operations.

As mentioned earlier in this chapter, all products are immediately recalled if any product exceeds $50 \mathrm{~Bq} / \mathrm{kg}$ of radioactive cesium. On February 27, 2014, such an incident happened for the first time. A sample taken from one particular species of ocean perch (Helicolenus hilgendorfi: Japanese name yumekasago) was measured as having $112 \mathrm{~Bq} / \mathrm{kg}$ of radioactive cesium. The sample was measured using a regular checking process conducted by the Fukushima FCA at the landing site in Iwaki. The Fukushima FCA immediately decided to stop distributing yumekasago from Iwaki.

The same species was also landed on the previous day (February 26, 2014) at Soma, which is the other port designated as a landing site for the trial operations. Although yumekasago samples inspected at Soma were below the $50 \mathrm{~Bq} / \mathrm{kg}$ threshold, the Fukushima FCA decided to recall all yumekasago landed at Soma the previous day from the middlemen and retail stores. According to the records of the Fukushima FCA, $33.5 \mathrm{~kg}$ of yumekasago were landed on February 26, 2014. Some had already been sold to consumers, but retail stores posted a message to consumers that they would recall the product and provide the corresponding refund.

All yumekasago from the waters of Fukushima disappeared from the market from 27 February until September 1, 2014, when the Fukushima FCA decided to restart trial operations and distribution for this species based on the consensus decision of the Fukushima Prefectural Fisheries Reconstruction Committee, which reviewed the outcome of recent testing of radioactive cesium contaminations in samples of yumekasago.

\subsection{Future Perspectives for Fukushima Fisheries}

The Fukushima FCA started its trial operations in June 2012 to target species occurring in offshore areas. It subsequently included species from the mid-surface layer of the coastal areas outside the $20 \mathrm{~km}$ radius from the nuclear power plant. The landing amount of the trial operations is around 1/30th of that harvested by commercial fisheries before the disaster. The full recovery of commercial fisheries in Fukushima has yet to be achieved. As of January 2015, the sale and marketing of 35 marine species are prohibited (Fukushima Prefecture 2015). These species typically live on the sea bottom of very near-shore areas. Full recovery of Fukushima fisheries cannot be realized until the government lifts the sales prohibition on all remaining marine species, but the timing of such a decision remains unclear.

At the same time, there are several issues that need to be addressed. These include issues related to weak consumer confidence following the nuclear power 
plant accident. Numerous incidents of weak consumer confidence in fisheries products from the tsunami-affected areas have been reported in newspapers and other media in Japan. Increased communication between producers and consumers assist consumer confidence. In order to increase communication between producers and consumers, it could be effective to shorten the distribution channel. Domestic fish distribution in Japan is composed of multiple layers of traders with two stages of wholesale markets: at the landing site and the consumption site. The first landing site handles the harvested fish and includes middlemen and distributors, while the consumption site wholesale market (e.g., Tsukiji Market in Tokyo) is located in cities and includes wholesalers and brokers. Retailers are then added to the value chain. Information about the production site is hard to communicate to consumers across this long chain. Improved communication and the establishment of accurate traceability mechanisms in the value chains can play a role in reducing consumer concerns (Yagi 2013).

Reforming the value chains for fishery products can help to reverse the current weak position of producers in the value chain compared with retailers (Sakai et al. 2012; Nakajima et al. 2011, 2014), and it can provide a solution to the economic weakness of Japan's fish harvesting sectors as a whole that pre-dates the March 2011 disaster. Even before the tsunami, the Ministry of Agriculture, Forestry and Fisheries pointed out that, while producers receive $24.7 \%$ of the retail price of the fish, retailers receive $38.5 \%$ and middlemen/distributers receive the remaining share (36.8\%) (Fisheries Agency of Japan 2009). It is extremely difficult to raise the price of fishery products in retail markets in the midst of weak consumer confidence. To enlarge the share of producers in the value chain, one possible option could take the form of new e-commerce business mechanisms to sell products more efficiently to urban consumers; any other forms of direct marketing to consumers would also be useful.

Open Access This chapter is distributed under the terms of the Creative Commons Attribution Noncommercial License, which permits any noncommercial use, distribution, and reproduction in any medium, provided the original author(s) and source are credited.

\section{References}

Fisheries Agency of Japan (2009) The fisheries white paper in 2009 issued by the Fisheries Agency of Japan. http://www.jfa.maff.go.jp/j/kikaku/wpaper/h21/gaiyou.html. Accessed Feb 2014 (in Japanese)

Fisheries Agency of Japan (2012) Q \& A on the power-plant accident. Homepage of fisheries agency. http://www.jfa.maff.go.jp/j/sigen/gensiryoku/index.html. Accessed Aug 2012 (in Japanese)

Fisheries Agency of Japan (2014a) The great East Japan earthquake's impact on fisheries and future measures. http://www.jfs.maff.go.jp. Accessed Dec 2014 (in Japanese)

Fisheries Agency of Japan (2014b) Questions and answers on fisheries. http://www.jfa.maff.go.jp/ j/kakou/Q_A/index.html. Accessed Feb 2014 (in Japanese) 
Fukushima Prefecture (2011) Marine fishery production statistics of 2010. http://www.pref. fukushima.lg.jp/sec/36035e/suisanka-toukei-top.html. Accessed Jan 2015 (in Japanese)

Fukushima Prefecture (2012) Marine fishery production statistics of 2011. http://www.pref. fukushima.lg.jp/sec/36035e/suisanka-toukei-top.html. Accessed Jan 2015 (in Japanese)

Fukushima Prefecture (2013) Marine fishery production statistics of 2012. http://www.pref. fukushima.lg.jp/sec/36035e/suisanka-toukei-top.html. Accessed Jan 2015 (in Japanese)

Fukushima FCA (2014) A list of marine species permitted for the limited experimental operations in Fukushima fisheries. http://www.jf-net.ne.jp/fsgyoren/siso/buhin/taisyousyu.pdf. Accessed Feb 2014 (in Japanese)

Fukushima Prefecture (2014) Homepage of Fisheries Division, Fukushima prefecture. http:// wwwcms.pref.fukushima.jp/pcp_portal/PortalServlet. Accessed Feb 2014 (in Japanese)

Fukushima Prefecture (2015) Discussion material for "Fukushima Prefectural Fisheries Reconstruction Committee." Materials prepared by Fukushima prefecture and distributed to the press and committee members on 22 Jan 2015

Furukawa F, Watanabe S, Kaneko T (2012) Excretion of cesium and rubidium via the branchial potassium-transporting pathway in Mozambique tilapia. Fish Sci 78:197-602

Ibaraki Prefecture (2014) Restricted items for marketing and distributions as of February 21, 2014. http://www.pref.ibaraki.jp/nourin/gyosei/housyanou_jyouhou.html\#4. Accessed Feb 2014 (in Japanese)

International Atomic Energy Agency (2004) Sediment distribution coefficients and concentration factors for biota in the marine environment. Technical report 422, Vienna

Kikkawa T, Yagi N, Kurokura H (2014) The state of concentration of radioactive cesium in marine organisms collected from the Fukushima coastal area: a species by species evaluation. Bull Jpn Soc Fish Sci 80:27-33 (in Japanese)

Ministry of Agriculture, Forestry and Fisheries, Japan (2012) Basic statistical data on damages in agriculture, forestry and fisheries caused by the Great East Japan Earthquake. http://www.maff. go.jp/j/tokei/joho/zusetu/pdf/00_2406all.pdf. Accessed Jan 2015 (in Japanese)

Miyagi Prefecture (2014) Restricted items for marketing and distributions as of February 18, 2014. http://www.pref.miyagi.jp/uploaded/attachment/245220.pdf. Accessed Feb 2014 (in Japanese)

Nakajima T, Matsui T, Sakai Y, Yagi N (2011) An approach to capture changes in asymmetric price transmission: rolling window TAR estimations using the blue fin tuna data. J Int Fish $10: 1-18$

Nakajima T, Matsui T, Sakai Y, Yagi N (2014) Structural changes and imperfect competition in the supply chain of Japanese fisheries product markets. Fish Sci 80:1337-1345

Sakai Y, Nakajima T, Matsui T, Yagi N (2012) Asymmetric price transmission in the Japanese seafood market. Bull Jpn Soc Fish Sci 78:468-478 (in Japanese)

Wada T, Nemoto Y, Shimamura S, Fujita T, Mizuno T, Sohtome T, Kamiyama K, Morita T, Igarashi S (2013) Effects of the nuclear disaster on marine products in Fukushima. J Environ Radioact 124:246-254

Yagi N (2013) Challenges faced with fishing industries in Fukushima and their long-term solutions. Bull Jpn Soc Fish Sci 79:88-90 (In Japanese)

Yagi N (2014) The state of fishing industry in Fukushima after the nuclear power plant accident. Glob Environ Res 18:65-72 